Revista lus et Praxis, Año 25, № 2, 2019, pp. 487 - 504

ISSN 0717 - 2877

Universidad de Talca - Facultad de Ciencias Jurídicas y Sociales

Una justificación de los tributos redistributivos

basada en el valor de la libertad

Cristián Augusto Fatauros

Trabajo recibido el 4 de enero de 2019 y aceptado el 12 de mayo de 2019

\title{
Una justificación de los tributos redistributivos basada en el valor de la libertad
}

\section{THE VALUE OF LIBERTY AS A RATIONALE FOR REDISTRIBUTIVE TAXATION}

\section{Cristián Augusto Fatauros ${ }^{*}$}

\begin{abstract}
RESUMEN
La justificación filosófica de los tributos redistributivos reciente ha comenzado a debatirse en las discusiones sobre reforma tributaria. Este trabajo ofrece una reconstrucción del valor de la libertad como justificación de los tributos redistributivos. El principal argumento afirma que proteger la libertad de todos los ciudadanos de manera igual exige financiar el funcionamiento eficiente de las instituciones, pero, además, demanda que los recursos financieros sean redistribuidos de manera aproximadamente igual. Esto es así porque la realización de una sociedad justa implica que los ciudadanos puedan hacer un uso efectivamente equivalente de las libertades que están formalmente protegidas. De lo contrario, las libertades de todos los ciudadanos no están protegidas por igual.
\end{abstract}

\section{ABSTRACT}

Redistributive taxes and their philosophical justification has only recently begun to be debated in contemporary discussions on tax reform. In this paper I present a reconstruction of the value of liberty as a plausible and attractive justification of redistributive taxation. The main argument states that equal protection of citizens' liberty requires economic resources to efficient institutions, but, in addition, it requires approximately equally redistribution of economic resources among the population. A just society implies citizens who can make effective and approximately equal use of the liberties that are formally protected. Otherwise, the liberties of all citizens are not equally protected.

\section{Palabras CLAVE}

Rawls, igualdad aproximada, principio de la igual libertad, suficiencia

KEY WORDS

Rawls, Equality, Equal Liberty, Sufficiency

\footnotetext{
* Consejo Nacional de Investigaciones Científicas y Tecnológicas (Conicet). Centro de Investigaciones Jurídicas y Sociales (CIJS). Unidad Ejecutora Mixta. Córdoba, Argentina. Correo electrónico: fatauros. cristian@conicet.gov.ar. Doctor en Derecho y Ciencias Sociales, Universidad Nacional de Córdoba. Investigador asistente en el Consejo Nacional de Investigaciones Científicas y Técnicas (Conicet). Profesor auxiliar en la Cátedra de Ética y en la Cátedra de Filosofía del Derecho, Facultad de Derecho de la Universidad Nacional de Córdoba (UNC). Ha sido investigador visitante en Bélgica, Chile y Dinamarca. Actualmente trabaja sobre teorías de la justicia distributiva y su intersección con la filosofía política del federalismo.
} 


\section{Una justificación de los tributos redistributivos basada en el valor de la libertad}

Las instituciones tributarias, como en general las instituciones jurídicopolíticas, constituyen medios para alcanzar objetivos sociales y políticos ${ }^{1}$. Sin embargo, no cualquier objetivo social o político es moralmente valioso y, por lo tanto, digno de persecución. Además, las instituciones deben satisfacer ciertos criterios de justicia para que la distribución de libertades, oportunidades y bienes económicos que ellas realizan sea considerada justa. Muchas teorías de la justicia comparten la idea de que un criterio adecuado para distribuir la protección de las libertades más básicas debería establecer un sistema que permita libertades de la manera más extensa e igualitaria posible ${ }^{2}$. Entre las libertades más importantes que se deberían proteger encontramos aquellas que son propias de una sociedad democrática constitucional, tales como la libertad de expresar las opiniones políticas o la libertad de contratar o ejercer libremente el comercio. Esta protección como condición moral de las instituciones podría sugerir que una economía de mercado abierto y competitivo sería preferida por sobre una economía centralmente dirigida. En esta última, los arreglos jurídico-políticos asegurarían un esquema de libertades menos extenso, esto es, con menos opciones para organizar nuestra vida económica.

Mi propósito en este trabajo es discutir precisamente esa tesis. Argumentaré que no deberíamos considerar que una sociedad con un esquema de libertades sin restricciones posee un valor supremo, y, es más, sostendré que una sociedad en la que existen mayores restricciones a las libertades sería preferible desde el punto de vista de la justicia distributiva, si están distribuidas de manera igual. Para desarrollar el argumento, primero analizaré el componente liberal de una de las teorías igualitarias más importantes en el debate contemporáneo. Luego de haber esclarecido esto, discutiré una concepción que afirma que la libertad es un valor que se opone a la realización plena del valor de la igualdad ${ }^{3}$.

\footnotetext{
1 Aunque también pueden ser consideradas como la materialización de un valor intrínseco. Así, alguien podría afirmar que las instituciones jurídicas y los tributos representan el valor del reconocimiento ciudadano recíproco. Según estas concepciones, los tributos podrían justificarse como herramientas que permiten alcanzar un cierto objetivo, como un estado de cosas, y justificarse como la expresión de una práctica que es valiosa por sí misma. Véase SafFie Gatica (2013).

2 Según Will Kymlicka, esta es una de las exigencias de justicia rawlsiana que menos controversias genera. Véase Krmlicka (2002), p. 57.

3 Para algunos autores, la concepción rawlsiana es igualitarista solo en apariencia y en parte se debe a su concepción de libertades negativas, su desconocimiento de la dimensión política de los impuestos (solo afectados a la recaudación fiscal) y su concepción de los impuestos como una contraprestación de la protección del derecho "natural" de propiedad. Véase SAfFie Gatica (2012), pp. 187 y ss.
} 


\section{Redistribución tributaria}

La distribución económica es una consecuencia producida de manera intencional y directa por la implementación de ciertas políticas públicas, i. e., un resultado establecido por las instituciones. En algunos casos, las instituciones explícitamente introducen reformas y esto conlleva cambios respecto a una distribución económica previa. En otros casos, las instituciones generan un resultado que, aunque no es establecido institucionalmente, puede ser previsto ${ }^{4}$.

Ahora bien, que un esquema institucional tributario sea moralmente correcto o no no depende de que los tributos sean aplicados una vez que los ciudadanos hayan obtenido sus ingresos (aplicación ex post). Los tributos podrían ser determinados de antemano (aplicación ex ante). Por ejemplo, en algunos esquemas institucionales el empleador tiene una obligación de retener un porcentaje del sueldo que recibe un trabajador, en concepto de tributos sobre las ganancias. Esto quiere decir que la justicia de un tributo no depende de que se respete o no la propiedad privada, y sí, en cambio, de su compatibilidad con un esquema de derechos y libertades moralmente correcto. Esto quiere decir que el momento en que se aplican los tributos no es normativamente relevante. Lo relevante sería que los tributos no infrinjan las libertades básicas de los ciudadanos 5 .

Pero, antes de llevar adelante una evaluación sobre cómo debería implementarse un esquema de tributos e identificar sus consecuencias económicas, es necesario hacer ciertas aclaraciones. Algunos tributos están pensados para financiar al Estado y el funcionamiento de nuestras instituciones. Esta justificación es más cercana a la compensación por una prestación de servicios y su imposición quizás debería tener que adecuarse a un criterio basado en el beneficio recibido ${ }^{6}$. También deben distinguirse los tributos que compensan los daños producidos por externalidades negativas una cierta actividad lícita. En este caso, el criterio adecuado quizás debería estar basado en la correcta distribución de la carga del costo de oportunidad social que exige neutralizar la externalidad negativa ${ }^{7}$. Estos casos representan una idea de compensación o retribución que no necesariamente exige una redistribución. Es así que los

\footnotetext{
${ }^{4}$ La distinción entre estos modos de producir un resultado institucional pertenece a Thomas Pogge. Véase Pogge (1989), pp. 44 y ss.

${ }^{5}$ BARRY (2014).

${ }^{6}$ De acuerdo con Bruno Verbeek, el principio de los beneficios no es plausible, ya que no existe una base neutral respecto de la cual puedan calcularse los beneficios obtenidos. Adicionalmente, una base comparativa para calcular los beneficios no permite concluir cuánto se debe contribuir. Véase VERBEEK (2015).

7 Esto va en consonancia con la idea dworkiniana de hacer a las personas responsables de los costos que implica tener la porción distributiva que se adapta a sus ambiciones. Véase DwORKIN (1981b).
} 
tributos redistributivos no son necesariamente redistributivos por el cómo se utilizan los fondos tributados, sino porque constituyen una carga económica que se coloca sobre los hombros de los que ganan más para mejorar la posición de los que ganan menos.

\subsection{Críticas fundadas en la protección de las libertades}

Ahora bien, la libertad de poseer propiedad de manera exclusiva sobre los medios de producción es considerada una de las más importantes en la naturaleza del moderno Estado de derecho ${ }^{8}$. Un esquema lo más extenso posible de la libertad de poseer propiedad exige respetar la posesión y el uso exclusivo de los recursos económicos ${ }^{9}$. Resulta obvio que el ejercicio del derecho de propiedad exclusiva se ve limitado si se imponen cargas tributarias con fines redistributivos en el sentido que ha sido definido más arriba ${ }^{10}$.

En su concepción de justicia, John Rawls propone una idea de sociedad que denomina "democracia de propietarios", en la que rige un capitalismo de mercado con intervención estatal ${ }^{11}$. Este esquema de instituciones democráticas garantiza la primacía de la igual libertad, pero hace falta identificar cuáles son las libertades que ineludiblemente se debe garantizar y proteger de manera igual para todos. Es necesario, además, justificar esa selección, justificar por qué algunas libertades son más importantes que otras y también por qué son más importantes que otros bienes, v. g. las oportunidades sociales. ¿Por qué la libertad de expresión debería ser protegida? ¿Por qué es más importante la libertad de expresión que la libertad de comprar moneda extranjera? Además, ¿por qué es más importante la libertad de expresión que la oportunidad de acceder a la educación universitaria?

Ahora bien, cuando la libertad se interpreta desde un punto de vista negativo, ser libre implica no sufrir interferencias y se podrían derivar al menos tres razones en contra de los tributos redistributivos ${ }^{12}$. En primer lugar, los tributos

\footnotetext{
${ }^{8}$ También puede ser considerada una condición de la igualdad en una democracia de propietarios. Véase Jackson (2012); Meade (2013); Williamson y O'neill (2012).

${ }^{9}$ Bajo una cierta concepción de la propiedad, esta consiste en derechos de uso, derechos de transferencia y cierta inmunidad o derecho a reclamar frente a la pérdida del bien poseído.

${ }^{10}$ El principio de justicia que protege las libertades afirma que "cada persona tiene un derecho igual al esquema de libertades más extenso que sea compatible con un esquema similar de libertades para los demás" [RAWLS (1971), p. 53].

11 RAwLS (1971), p. 242. Me refiero a la posibilidad de que las personas sean propietarias de los medios de producción económica. Este tipo de propiedad está expresamente excluido de la lista de libertades básicas incluidas en el principio de la igual libertad [Rawls (1971-1999), p. 54].

12 Sigo la reconstrucción realizada por Peter Vallentyne en ValLentrne (2012), p. 296.
} 
suponen una interferencia constante en la libertad individual. Esta objeción, sin embargo, depende de la periodicidad con que uno deba realizar el pago. $\mathrm{Si}$ el pago de los tributos fuese anual, la objeción pierde su fuerza. Lo que importa no es tanto la interferencia constante, sino la interferencia significativa. Los gravámenes sobre el dominio y el uso, incluso la obtención de riquezas, lesionarían significativamente la libertad individual ${ }^{13}$. Es necesario ofrecer un argumento para justificar por qué la protección de la igual libertad no incluye como libertad específicamente protegida la libertad de disponer ampliamente de mis bienes (por ejemplo, construyendo un edificio de tal manera que se impida la ventilación e iluminación de una pequeña casa vecina). Pero también debe ofrecerse un argumento sobre las razones que justifican que el derecho a expresar mis opiniones políticas de manera pública sí merezca esa protección ${ }^{14}$.

En segundo lugar, la intervención que se provoca podría equipararse a la explotación. Si existe redistribución, el que más gana debería trabajar algunas horas extras para otros, en particular para aquellos que ganan menos. Esto es otra manera de afirmar que es moralmente incorrecto interferir en la libertad de ser propietario exclusivo o de ganar dinero mediante el empleo de la propia fuerza trabajo. Lo moralmente incorrecto sería que yo no pueda libremente decidir qué hacer con mi tiempo de ocio. Quizás alguien podría objetar que, para mantener su derecho de propiedad exclusiva sobre algunos bienes, se deba pagar un canon ${ }^{15}$.

En tercer lugar, se podría objetar que los tributos redistributivos atentan contra los derechos de propiedad exclusiva sobre bienes externos. Esta objeción es mucho menos convincente porque supone que los derechos sobre los bienes externos no están sujetos a ninguna condición moral. Pero no hay razones para suponer que esto deba ser así, y, por ejemplo, los derechos de propiedad pueden estar sujetos a la condición de pagar ciertos tributos que serán determinados posteriormente a través de un procedimiento legislativo democrático. En ese caso, no podría válidamente afirmarse que los derechos de propiedad han sido violados solo por el hecho de que se deban pagar tributos.

\footnotetext{
${ }^{13}$ Hart afirma que un principio de justicia debería tener en cuenta libertades importantes como la libertad sexual y la libertad de consumir alcohol o drogas, por más que no sean consideradas libertades básicas. Véase Hart (1972) en Daniels (1975b), pp. 237-238.

14 Del mismo modo, tengo que mostrar por qué la libertad de ganar un sueldo sin tener que pagar impuestos no es una libertad básica o por qué no puedo cobrar un premio ganado en la Lotería Nacional sin tener que pagar un impuesto equivalente al $31 \%$ del premio.

15 Según Peter Vallentyne, esta objeción solo se aplicaría a los impuestos sobre las ganancias (income) [VALLENTYNE (2012), p. 297]. No estoy de acuerdo; en cualquier caso, uno terminaría haciendo algo que no quiere porque el Estado lo obliga a tributar.
} 
Es cierto que, dentro de la concepción rawlsiana de justicia, la libertad podría interpretarse negativamente, porque Rawls en principio pareciera considerar que las libertades, tanto en su concepción general como en su concepción especial, se definen de manera tal que cualquier persona tiene un derecho a no sufrir interferencias en sus acciones a menos que exista una justificación relevante para hacerlo. Incluso podríamos preguntarnos por qué algunas libertades son más importantes que otras. Es decir, preguntarnos por qué estaría justificado condicionar ciertas libertades, como la libertad de ejercer el comercio o la libertad de obtener ingresos, para expandir otras libertades en otros ámbitos, como por ejemplo para debatir y alcanzar una decisión colectiva sobre ciertas cuestiones políticas.

A menos que se proponga un criterio externo para ordenar jerárquicamente las libertades y postular que algunas libertades imponen condiciones sobre otras, la prioridad parece irrazonable ${ }^{16}$. Ahora bien, supongamos, en beneficio del argumento, que se pueda dar sentido a la idea de prioridad de algunas libertades por sobre otras. Es decir, que aceptamos que algunas libertades y derechos tienen condiciones para poder proteger otras libertades y derechos. Aun así, esto no solucionaría el problema de tener que acudir a un punto de vista de un individuo concreto que haya sido afectado. Ante un conflicto de intereses, cada individuo valora de manera diferente la satisfacción de los intereses de acuerdo a su particular sistema de preferencias. Nuevamente pareciera que, si aceptamos una concepción de libertad negativa, hace falta un criterio para identificar las libertades que no deben ser interferidas ${ }^{17}$. Esto podría dar la razón a la crítica articulada por H. L. Hart, cuando afirma que es perfectamente racional adoptar una regla que restrinja ciertas libertades para obtener ventajas económicas, siempre y cuando esta restricción no sea permanente ${ }^{18}$. Hart niega que exista un fundamento racional para aceptar la restricción a priori de arreglos institucionales futuros, pero acepta compromisos temporales.

\subsection{Las desigualdades económicas que afectan la igualdad en libertades}

Ahora bien, un punto que no es posible ignorar es el de las desigualdades económicas. Las desigualdades económicas pueden llevarnos hacia una desigualdad, no en la protección, pero sí en el ejercicio de las libertades. Quienes se encuentran en el nivel más bajo de ingresos no pueden hacer un ejercicio de sus libertades semejante al que hacen quienes se encuentran en el nivel más

16 Daniels (1975 b), p. 240.

17 Daniels (1975 b), pp. 241-243.

18 Daniels (1975 b), p. 251. 
alto. Esto es casi obvio, pero lo que no es obvio es por qué. El valor de una libertad (y su ejercicio) dependerá de la riqueza económica de cada persona y, por eso, las diferencias económicas se traducirán en diferencias en el ejercicio efectivo de las libertades ${ }^{19}$. La incapacidad de beneficiarse de cierta libertad por carecer de medios económicos no es una limitación institucional, pero es una limitación significativa y preocupante.

¿Es que acaso los tributos provocan desigualdades económicas que impactan limitando significativamente el valor de las libertades? ${ }^{20}$ Para Thomas Pogge, importa tanto el alcance institucional como la seguridad efectiva de las libertades. Por ejemplo, puede ser que todos los ciudadanos tengan sus libertades protegidas institucionalmente, pero en la práctica quienes viven en barrios marginales sufran discriminaciones selectivas cuando transitan por la zona comercial de la ciudad $^{21}$. Aunque el alcance es igual, la seguridad no. Por esto, autores como Norman Daniels afirman que es un error desatender las amenazas de las diferencias económicas sobre la protección igual de las libertades ${ }^{22}$. Para este autor, la protección y garantía de las libertades básicas debería garantizar la protección institucional de una libertad de manera igual y garantizar su valor de manera igual. En otras palabras, debería garantizar también que un ciudadano pudiese ejercitar su libertad de un modo efectivamente igual al de cualquier otro.

Si las personas son libres de realizar intercambios voluntarios de bienes y servicios que a largo plazo generan desigualdades económicas profundas, ¿por qué deberían importarnos estas desigualdades económicas en el largo plazo? Es decir, si esas desigualdades económicas no han sido establecidas legalmente y solo son el resultado de las transacciones particulares -el juego de la oferta y

${ }^{19}$ Daniels (1975 b), p. 179.

${ }^{20}$ Thomas Pogge traslada la protección de la libertad a un determinado alcance institucional, pero también a una dimensión de protección fáctica, a la que denomina seguridad efectiva de la protección. Pogge (2007), p. 83.

${ }^{21}$ Este es el caso de los jóvenes que habitan barrios marginales y son repetidamente detenidos por la policía para averiguar sus antecedentes penales. En particular en la ciudad de San Francisco, provincia de Córdoba, se han presentado casos de hostigamiento policial a los que se denunció mediante la figura del habeas corpus preventivo. Véase: http://www.comercioyjusticia.com.ar/2012/10/02/hacenlugar-a-habeas-corpus-por-hostigamiento-policial/.

${ }^{22}$ Este problema también ha sido discutido por Philippe van Parijs. Este autor argumenta que, para que todos los individuos tengan y disfruten de igual libertad "real", deben otorgarse "oportunidades" para que los individuos hagan "... lo que pudieran querer hacer". Sobre la diferencia entre libertad formal y sustantiva, véase VAN PARIJS (1995), pp. 34-46. Sin embargo, la concepción de justicia como libertad real para todos no se diferencia demasiado en los supuestos teóricos respecto de la concepción rawlsiana de justicia como equidad. 
demanda en un mercado competitivo--, la intervención estatal constituye una intromisión ilegítima en los actos libres y voluntarios de las personas ${ }^{23}$.

No obstante, las desigualdades económicas sí son relevantes. Las desigualdades económicas son generadas por las instituciones y precisamente por ello pueden ser rectificadas institucionalmente ${ }^{24}$. Tanto los efectos generados como los efectos establecidos son efectos que las instituciones producen. Dado que son las instituciones las que regulan la distribución de los derechos sobre los bienes económicos, las desigualdades económicas no pueden ser consideradas un resultado "natural" permitido por las instituciones, como, por ejemplo, las desigualdades naturales que se producen cuando se decide no desarrollar remedios para enfermedades que pueden evitarse. La pobreza y la desigualdad son resultados producidos institucionalmente ${ }^{25}$. Si este razonamiento es correcto, es plausible pensar que una distribución desigual del ejercicio de una libertad produce una distribución desigual de aquello que hace importante a la propia libertad. Es decir, si admitimos que una persona no pueda expresar sus opiniones políticas de manera igual que el resto de sus conciudadanos porque sus ingresos económicos son escasos, la libertad de expresar públicamente la propia opinión política no es igualmente protegida y su libertad vale menos.

El argumento es plausible. La protección igual de las libertades y de su valor está fundada en la misma premisa, a saber: que las desigualdades económicas y sociales convierten en ilusorio el efectivo ejercicio de la libertad. Ambas desigualdades son obstáculos relevantes para el estatus de igual ciudadano y corresponde preguntarnos cómo superar esos obstáculos y no, en cambio, cómo pudieron haber surgido ${ }^{26}$. Si estamos de acuerdo con Rawls sobre que las restricciones legales son relevantes, deberíamos justificar por qué no debemos

${ }^{23}$ Nozick (1990), pp. 155-167.

${ }^{24}$ Me apoyo en la interpretación de Pogge para la reconstrucción de esta réplica. Véase Pogge (1989), pp. 44 y ss.

${ }^{25}$ La distinción entre efectos "producidos" y efectos "permitidos" institucionalmente es discutible. De hecho, una crítica a la noción de "bienes sociales primarios" afirma que la salud es también un bien social que se distribuye institucionalmente. Véase Riвотта (2009), pp. 100 y ss. Daniels afirma que los bienes sociales primarios pueden incluir la cura para discapacidades y enfermedades, si considerásemos que los bienes sociales son determinantes de algunas enfermedades y que la salud podría ser protegida también garantizando la igualdad equitativa de oportunidades. Véase Daniels (2003), pp. 256-263. No obstante, creo que la distinción entre efectos "permitidos" y "producidos" es suficientemente útil para comprender la preocupación por la estructura institucional.

${ }^{26}$ En palabras de Philippe van Parijs, para proteger una libertad y su valor es necesario preguntarse "cuáles son los obstáculos que la estructura institucional debería abolir" (PONER énfasis en itálicas al texto destacado). VAN PARIJS (1995), p. 44.. 
preocuparnos por las restricciones económicas ${ }^{27}$. Autores rawlsianos como Norman Daniels hacen hincapié sobre este punto al sostener que, si la protección de las libertades es tan importante, no se debería admitir ninguna restricción, ni económica ni legal. Por ejemplo, el sistema de propiedad privada no debería admitir desigualdades económicas exorbitantes que producen restricciones y obstáculos a la plena satisfacción del principio de la igual libertad ${ }^{28}$. La estructura institucional de la propiedad privada moralmente valiosa sería aquella en la que ninguna persona tuviese más obstáculos que los demás ${ }^{29}$.

En este punto, la cuestión gira en torno a cómo determinar el criterio para evaluar si las libertades están protegidas de manera suficientemente igual y bajo qué condiciones se aplica este criterio. Creo que la noción de ciudadano libre e igual resulta iluminadora porque proporciona coherencia y sistematicidad al esquema de libertades a la vez que permite distinguir cuáles son las libertades políticas, cuáles son las libertades básicas y qué libertades no merecen una igual protección.

\section{Consideraciones sobre la idea de ciudadano}

A partir de las aclaraciones introducidas por Rawls en Political Liberalism $(\mathrm{PL})$, la idea de ciudadano cobra una relevancia fundamental ${ }^{30}$. La teoría rawlsiana ahora encuentra apoyo en una concepción normativa de persona representada como un ciudadano que participa en un proyecto social plural y que se relaciona con sus conciudadanos en términos de libertad e igualdad política ${ }^{31}$. Los ciudadanos deberían disfrutar de libertades "completamente adecuadas" para desarrollar sus virtudes cívicas. Rawls abandona la idea de que las libertades sean "lo más extensas posible". La idea de ciudadano es clave para comprender que la noción de libertad no protege una noción genérica de libertad ni una

27 Daniels (1975b), pp. 260-263.

${ }^{28}$ Daniels (1975b), p. 268.

29 Daniels (1975b), p. 268.

${ }^{30}$ Se alzaron numerosas críticas en su contra, de la teoría política rawlsiana. Algunas discutían la particular forma de justificación filosófica que Rawls había ofrecido: BARRY (1995), Seleme (2003); otras discutían la particular concepción de persona que servía de apoyo a la teoría, ver Seleme (2004), y otras eran críticas internas. El libro Political Liberalism da respuesta a algunas de las objeciones en contra de los presupuestos metodológicos y al tipo de justificación filosófica presentada en A Theory of Justice. En particular, Political Liberalism modifica el carácter moral comprehensivo de la concepción de persona de la justicia como equidad. Ver Rawls (1993).

31 RAwlS (1993), pp. 289-290. Véase el trabajo de Hugo Seleme, quien defiende la consistencia de la teoría rawlsiana y sostiene que la neutralidad de la justicia como equidad está garantizada por una concepción neutral de persona. Ver Seleme (2004), pp. 75 y ss., y Rawls (1993), pp. xv-xvi, xl. 
concepción negativa de la libertad ${ }^{32}$. Las libertades y garantías que interesa proteger son aquellas que subyacen a nuestras instituciones políticas y jurídicas ${ }^{33}$.

Instituciones justas exigen implementar condiciones sociales necesarias para el desarrollo adecuado de nuestras virtudes cívicas y el ejercicio pleno de nuestros derechos ciudadanos. Si una libertad puede considerarse una condición social necesaria para el desarrollo de los ciudadanos de una sociedad democrática y constitucional, entonces debe ser protegida ${ }^{34}$. He aquí un primer umbral que debe satisfacer cualquier esquema institucional que se considera justo.

\subsection{Primer umbral: Coherencia sistémica}

Un primer problema es que las libertades pueden colisionar entre sí. Por ejemplo, la libertad de usar mi propiedad de manera exclusiva puede chocar contra la libertad del lector de expresar su opinión. Si yo soy dueño de los principales medios de comunicación y me niego a darle a usted un espacio en los diarios, revistas y canales de televisión sobre los que tengo derecho a decidir el contenido, ¿estoy haciendo un ejercicio legítimo de mi libertad y, por lo tanto, es legítima la disminución del ejercicio de su libertad de expresión?

Para responder a esta pregunta podemos apelar a la noción de coherencia sistémica, según la cual las libertades pueden ser restringidas o comprometidas a favor de otras libertades básicas. Esto no exige que las libertades básicas sean igualmente satisfechas ("to be equally provided for"), sino que debe implementarse un esquema institucional de libertades que las asegure coherentemente y para todos los ciudadanos ("is secured equally for all citizens") ${ }^{35}$. En otras palabras, la exigencia de igual libertad no implica libertades aseguradas en la misma extensión o del mismo modo, sino más bien que sean coherentemente aseguradas para todos los ciudadanos, sin distinciones basadas en su sexo, grupo étnico, género, grupo social o ingresos económicos. La regulación coherente de las libertades básicas debe garantizar, por lo menos, un mínimo ejercicio de

\footnotetext{
32 Por el contrario, protege libertades muy específicas, particularmente "... libertades y garantías constitucionales, tal como las encontramos, por ejemplo, en diversas cartas de derechos y declaraciones de los derechos del hombre". Rawls (1993), p. 292.

33 RAwLS (1993), p. 293.

${ }^{34}$ En ausencia de circunstancias favorables para proteger las libertades de todos los ciudadanos de igual modo, las personas menos aventajadas deberían aceptar comprometer algunas libertades a cambio de obtener un incremento futuro en la protección de las libertades o en bienes económicos. Esto no implica que las instituciones sean perfectamente justas, sino que son razonablemente justas dadas las condiciones sociales vigentes.

35 Rawls (1993), p. 295.
} 
cada una de ellas y "preservar intacto un rango central de aplicación de cada libertad básica" ${ }^{\prime \prime}$.

De este modo, la regulación permite asegurar las libertades de manera diferente, con una protección adecuada a cada ejercicio mediante instrumentos jurídicos específicos. Por ejemplo, la libertad de participación política (arts. 16: "igualdad ante la ley", 22: "gobierno representativo", 36: "derecho al sufragio universal, igual, secreto y obligatorio" de la Constitución argentina) y la libertad de opinión y conciencia (arts. 19 y 32 de la Constitución argentina) no necesariamente debe ser protegida por igual ni a través de las mismas instituciones. Aunque la libertad de conciencia debe ser especialmente protegida en el ámbito contractual, ya que es moralmente inadmisible que los contratos impongan la obligación de abandonar las propias creencias religiosas, el derecho a mantener en secreto una relación contractual no es tan significativo para el desarrollo de las capacidades ciudadanas.

Una vez dado este paso, el primer problema se resuelve de manera sencilla. Es posible distinguir entre las libertades básicas y las otras libertades sin apelar a preferencias subjetivas, ni tampoco es necesario el punto de vista particular de algún ciudadano. Por todo esto, una libertad específica, como la libertad de transferir bienes o la libertad de ejercer una industria lícita y obtener ingresos económicos, no necesariamente se ve menoscabada por el hecho de que se deban pagar impuestos. Esas libertades no deben considerarse libertades básicas. Solo puede considerarse una libertad básica aquella que promueve mi desarrollo como ciudadano. Una regulación razonable de cualquier otra libertad debería considerarse moralmente admisible.

El ordenamiento jurídico constitucional de Argentina, en el artículo 14 bis de la Constitución, establece que "el trabajo en sus diversas formas gozará de la protección de las leyes, las que asegurarán al trabajador [...] participación en las ganancias de las empresas, con control de la producción y colaboración en la dirección". Además, este artículo reconoce el derecho a la "organización sindical libre y democrática, reconocida por la simple inscripción en un registro especial".

\footnotetext{
36 RAwls (1993), p. 296. Alexandra Couto realiza una interesante aplicación de la distinción "regulación/ restricción" para disolver el conflicto entre la libertad de expresión -que protege el contenido, pero no la forma de expresar una opinión o idea- y los derechos de copyright de creadores y autores -que protegen la forma, pero no el contenido de la expresión de una opinión o idea-. De acuerdo con ella, la concepción rawlsiana evita el conflicto entre esta libertad y estos derechos porque se aplican a diferentes aspectos de la expresión de una opinión o idea. Ver Couto (2008), p. 179. Distinguir entre regulación y restricción ayuda a entender por qué las regulaciones se justifican con base en el valor de la razón pública.
} 
La fundamentación de tan extenso derecho no podría interpretarse sin una colisión con el derecho constitucional de "trabajar y ejercer toda industria lícita; [...] de comerciar; de usar y disponer de su propiedad", tal como dispone el artículo 14 de la Constitución argentina y también en franca contradicción con lo dispuesto en el artículo 17, que proclama "la propiedad es inviolable, y ningún habitante de la Nación puede ser privado de ella, sino en virtud de sentencia fundada en ley".

Es obvio preguntarse si las libertades y derechos contemplados en beneficio de los trabajadores que impactan sobre la libertad de los empresarios de decidir libremente constituyen una libertad cuyo ejercicio debería ser protegido, o constituyen una libertad que no debería tener ninguna prioridad y debería ser considerada como el resto de las libertades. ¿Es necesaria para la protección de la igual ciudadanía garantizar la participación de los trabajadores en las ganancias de las empresas? ¿Constituye una regulación arbitraria y por ello una restricción de la libertad del ciudadano que pretende dedicarse al comercio o una restricción indebida del derecho de usar la propiedad privada del modo que cada comerciante y empresario decida?

Si consideramos que la imposición de tributos está justificada, y que los tributos son un mecanismo efectivo para la redistribución de la riqueza, no debería ser un obstáculo considerar la participación de los trabajadores en la generación de riquezas. De manera análoga, ambas formas institucionales imponen una condición sobre la libertad de comerciar, de transferir la propiedad o de ejercer la industria lícita. Quien decida dedicarse al comercio puede hacerlo. Es un proyecto de vida perfectamente viable y de ningún modo puede pensarse que queda "obturado" por las restricciones que imponga un Estado que pretende limitar la disposición de la propiedad privada. Siempre deberá tenerse en cuenta los modos en que esto debe articularse para regular de una manera razonable.

¿Es el derecho a participar de las ganancias de una empresa una libertad básica que debe proteger el Estado si pretende limitar la desigualdad económica para evitar que el ejercicio de otras libertades se vuelva ineficaz? Desde un punto de vista de la igual libertad, la respuesta positiva se impone. En el próximo apartado analizaremos si esta libertad debería poder ser renunciada o enajenada.

\subsection{Segundo umbral: Capacidades ciudadanas}

Ahora bien, un segundo problema podría ser por qué no proteger las libertades que cada individuo considere importantes. Por ejemplo, ipor qué no proteger la libertad de comprar moneda extranjera si una persona prefiere ahorrar en dólares? ¿Por qué no debería tener el mismo nivel de protección que una libertad básica? Pues bien, si cayese bajo la protección del principio de la igual libertad cualquier libertad que cualquier ciudadano juzgara importante, 
deberían destinarse recursos que implican debilitar la protección de las libertades básicas ${ }^{37}$.

Las instituciones que protegen el ejercicio de las libertades deben evaluarse en diferentes niveles. Un primer nivel evalúa si el hecho de regular el ejercicio de una libertad para evitar conflictos con otras libertades no convierte en vacío o insignificante ese ejercicio ${ }^{38}$. Un segundo nivel se da en la evaluación del esquema institucional que define las libertades básicas. El esquema institucional que garantice las libertades debe brindar una protección institucional igualmente segura para todos los ciudadanos. Si existen hechos sistemáticos de violación de libertades, entonces la igualdad en la garantía de libertades no se satisface. Por último, un tercer nivel de evaluación exige lograr condiciones sociales adecuadas que posibiliten a los ciudadanos un desarrollo y ejercicio pleno e informado de sus capacidades cívicas ${ }^{39}$. Estas condiciones deben ser igualadas.

Estas exigencias se traducen institucionalmente en derechos y libertades que son irrenunciables para la ciudadanía. Del mismo modo que los derechos de los trabajadores son irrenunciables, mientras que los derechos de los empresarios sí lo son, el derecho de disponer de la propiedad privada encuentra una clara limitación en el financiamiento de los partidos políticos. Por ejemplo, en la provincia de Córdoba, el financiamiento está limitado: "Ninguna persona humana puede efectuar aportes para la misma campaña electoral superiores a la suma equivalente a cinco (5) unidades de Salario Mínimo, Vital y Móvil" y las personas jurídicas también están limitadas en el uso que pueden hacer

\footnotetext{
37 Además, no es claro cómo deberían regularse coherente y públicamente las libertades que cada uno de los ciudadanos considerase importantes, sin vulnerar el ámbito de aplicación mínimo de cada una. RAwLS (1993), p. 296.

38 De acuerdo con Реттіт (2008), esta exigencia de regulación se desprende de la imposibilidad de definir las libertades específicas sin apelar a un esquema institucional específico que incluya reglas de coordinación. Por supuesto que Pettit, en razón de su republicanismo consecuencialista, sostiene una versión algo diferente de la concepción rawlsiana de libertades básicas. Su versión exige que, si dos esquemas institucionales son posibles y uno de ellos protege mayor cantidad de libertades específicas, ese es el esquema que debe ser implementado. Por eso, si el esquema A garantiza las libertades $L^{1} a L^{n}$, y el esquema $B$ garantiza las libertades $L^{1}$ hasta $L^{n+1}$, el segundo es el que debería ser implementado. Véase PetTit (2008), pp. 204-205. La libertad de expresar la propia opinión, por ejemplo, puede ser regulada con el propósito de permitir el ejercicio de la libertad de participación política de todos los ciudadanos. Es por eso que consideramos importante tener reglas de debate que regulen la duración y moderen los discursos parlamentarios cuando se expresan opiniones en los debates legislativos. Si todos los ciudadanos ejercieran al mismo tiempo la libertad de participar políticamente y de expresar la propia opinión, se convertiría en inútil esta libertad. Nadie podría aprovechar los beneficios de su ejercicio, que se verían frustrados por la falta de coordinación y cooperación. Peтtit (2008), pp. 204-209.

${ }^{39}$ Las capacidades de los ciudadanos son la capacidad de tener un sentido de la justicia por el que se evalúan las instituciones y las políticas públicas y la capacidad de tener una concepción del bien determinada. Véase RAwLS (1993), p. 332.
} 
para participar en el financiamiento, ya que solo "... pueden aportar un monto que no supere el dos por ciento $(2 \%)$ de los gastos permitidos para la campaña de que se trate" (art. 202, Ley No 9.571, Código Electoral de la Provincia de Córdoba). Además, "Sólo pueden contratar los espacios publicitarios destinados a propaganda y publicidad electoral, el Tribunal Electoral y el Responsable de Campaña Electoral de los partidos, alianzas o confederaciones políticas que participen en la compulsa electoral" (art. 216, Ley № 9.571, Código Electoral de la Provincia de Córdoba).

La cuestión es brindar igual protección al valor de las libertades políticas de participación y difusión de las ideas políticas de los distintos partidos, e indirectamente de la ciudadanía en general. Estas limitaciones no pueden renunciarse de manera unilateral ni pueden someterse a negociación por parte de los particulares. Forman parte de lo que se consideran "libertades políticas básicas", que deben mantener el valor igual para que el efectivo ejercicio de los derechos ciudadanos se mantenga protegido.

Un tercer problema es responder por qué no debería aplicarse un criterio maximizador sobre la protección institucional de las libertades básicas. ¿No es cierto que deseamos maximizar las oportunidades de ejercitar nuestras libertades básicas? Dicho de otro modo: ¿por qué la protección de las condiciones para ejercer las libertades básicas debe ser suficientemente protegida y no, en cambio, lo más extensamente posible protegida? Se hace necesario identificar las razones para no considerar relevantes las ganancias marginales que están por encima del umbral de suficiencia ${ }^{40}$. Para un liberal igualitario aplicar un criterio maximizador sería irrazonable ${ }^{41}$.

Primero, no es razonable maximizar las condiciones sociales esenciales en que se ejercita una libertad cívica si esto no se traduce en un incremento en la efectividad con que se desarrollan y ejercitan dicha libertad. Cuando un ciudadano hace un uso efectivo de su libertad de expresión, añadir más oportunidades en las que puede expresarse libremente no convierte este ejercicio en más efectivo, sino que extiende las oportunidades de hacerlo ${ }^{42}$. Por ejemplo, si un ciudadano puede expresar su opinión respecto de un tema importante de

\footnotetext{
40 Pogge (2007), p. 85.

${ }^{41}$ Sobre las dificultades de los criterios suficientistas, véase CASAL (2007), pp. 299-303. Las concepciones distributivas suficientistas sostienen que lograr el nivel de suficiencia es importante a la vez que restan importancia a los incrementos por encima de dicho nivel.

42 Sobre la posibilidad de que tanto la intensidad como la extensión de la libertad sean importantes, véase la discusión de Philip Pettit, respecto a la extensión que la libertad como no dominación debería tener y la diferencia entre los factores que comprometen y los que condicionan la libertad. РетTIT (1997), pp. 74-77.
} 
manera efectiva ante sus representantes una vez al mes, ¿en que lo beneficiaría tener una oportunidad de hacerlo una vez a la semana? Lo principal es que existan oportunidades significativas de ejercitar efectivamente las libertades. Si los ciudadanos pueden transmitir sus ideas públicamente sin restricción en cuanto a su contenido, existe un esquema institucional que protege este tipo de acciones y además su protección es efectivamente asegurada para todos; el hecho de incrementar las posibilidades de que alguien pueda transmitir sus ideas no hace que el ejercicio de su libertad sea más efectivo.

Segundo, es incorrecto maximizar las condiciones sociales en las que las libertades se ejercitan, porque estas condiciones sociales constituyen condiciones necesarias para llevar adelante una buena vida, pero no son condiciones suficientes. Las personas tienen compromisos y lealtades que dan sentido a su vida. Dichas creencias y valores en algunos casos exigen promover un cierto estilo de vida. El ejercicio de las libertades ciudadanas no debería entrar en conflicto con las demandas particulares que cada individuo tiene en razón de sus particulares creencias fundamentales ${ }^{43}$. Las libertades ciudadanas y las condiciones sociales esenciales para ejercerlas son valiosas, pero no agotan lo que es valioso para un ciudadano ${ }^{44}$.

Pensemos en el siguiente ejemplo. Carlos, un ciudadano de una sociedad bien ordenada, es una persona que disfruta llevar adelante una vida de placeres mundanos. Desde su punto de vista, es razonable tener aseguradas oportunidades para realizar un efectivo ejercicio de su libertad de expresar su opinión política, pero Carlos desea llevar adelante un plan de vida que implica disfrutar de sus preferencias más simples. Su interés en actividades placenteras y su interés en tener a su disposición oportunidades para ejercitar su libertad de expresión deberían ser compatibles. No sería razonable negar que tenga un interés en proteger y asegurar efectivamente dicha libertad, pero no estará interesado más allá de poder realizar un ejercicio efectivo y equivalente al que puede realizar cualquier otro ciudadano. Tal como lo afirma Harry Brighouse, las libertades políticas son el medio para alcanzar otro bien primario que todos desean tener asegurado de manera más o menos aproximada: influencia política ${ }^{45}$.

En la posición rawlsiana, las instituciones sociales justifican su existencia porque ofrecen un contexto necesario para desarrollar un proyecto de vida que

\footnotetext{
${ }^{43}$ En otra parte he analizado la objeción que afirma que la motivación egoísta de las personas, en sus decisiones individuales, afecta la distribución justa de los bienes socio-económicos. Fatauros (2012).

44 Rawls (1993), p. 333.

45 Brighouse (1997), p. 166.
} 
las personas consideran valioso ${ }^{46}$. Adicionalmente, la idea de tener un sentido de la justicia puede ayudarnos a comprender por qué las instituciones sociales son solo un medio para una vida valiosa. El deseo de comportarnos como se debe, y tratar a los demás como libres e iguales, no es todo lo que un buen ciudadano desea. Principalmente, desea llevar una vida valiosa, dentro de la cual la justicia es solo una parte de lo que considera bueno y valioso ${ }^{47}$.

Tal como he examinado, la concepción de ciudadano sobre la que se apoya justicia como equidad incorpora una dimensión de razonabilidad. Esto es, en la definición del punto de vista desde donde se evalúan los arreglos institucionales no debemos recurrir a los intereses y preferencias particulares de personas concretas con planes de vida determinados. Debemos recurrir a los intereses que una persona en tanto ciudadano participante de una empresa cooperativa para el beneficio mutuo desearía promover.

\section{Conclusiones}

En síntesis, para que un ciudadano tenga protegidos sus derechos y libertades todos los demás deberían gozar de una protección suficientemente igual. Al incorporar un criterio de igualdad aproximada para la distribución del valor de las libertades políticas se exigen condiciones sociales en las que todos puedan hacer un uso equivalente de sus libertades políticas. Estas exigencias institucionales señalan un límite respecto de la desigualdad y demanda una distribución que garantice a todos los ciudadanos un igual ejercicio de sus libertades cívicas. En el caso de la protección institucional de las libertades que no son políticas, nadie puede tener menos que una protección suficiente. En el caso de las libertades políticas, nadie puede tener más que una protección suficientemente equivalente.

La idea de igualdad y suficiencia equivalente funciona para asegurar que en una sociedad en la que se satisfacen los principios de justicia como equidad, una persona que logra acumular una gran cantidad de riqueza no perjudique la protección de los derechos y libertades de los demás ciudadanos. La exigencia de suficiencia se satisface si todos los ciudadanos tienen una oportunidad de ejercitar efectivamente su libertad de manera equivalente, aunque no todos tengan los mismos medios para ejercitar efectivamente su libertad.

Podemos afirmar, entonces, que para determinar si las libertades definidas institucionalmente son meramente formales es necesario evaluar si el procedimiento político es equitativo. Esto dependerá de si garantiza el valor equitativo

46 Rawls (1993), p. 334.

47 Rawls (1993), pp. 315 y ss. 
de las libertades políticas, la igualdad formal de las libertades básicas y conjuga estas garantías con la aplicación del principio de la igualdad equitativa de oportunidades y el principio de la diferencia, algo que excede largamente los límites acotados de este trabajo.

\section{BiBLIOGRAFÍA CITADA}

BARRY, Brian (1995): "John Rawls and the search for stability", en: Ethics (Vol. $\left.105, N^{\circ} 4\right)$, pp. 874-915.

BARRY, Christian (2014): "Redistribution", en: The Stanford Encyclopedia of Philosophy. Disponible en: http://plato.stanford.edu/archives/spr2014/entries/redistribution/ [31.11.2015]

Brighouse, Harry (1997): "Political equality in justice as fairness", en: Philosophical Studies (Vol. 86, No2), pp. 155-184.

Casal, Paula, (2007): "Why Sufficiency Is Not Enough", en Ethics (Vol. 117, № 2), pp. 296-326.

Couto, Alexandra (2008): "Copyright and Freedom of Expression: A Philosophical Map", en: A. Gosseries, A. Marciano y A. Strowel (eds.), Intellectual Property and Theories of Justice (UK, Palgrave MacMillan), pp. 160-187.

Daniels, Norman (1975a): Equal Liberty and Unequal Worth of Liberty. En N. Daniels (Ed.), Reading Rawls (Blackwell), pp. 253-281.

(1975b): Reading Rawls. Critical Studies on Rawls “A Theory of Justice" (USA: Basic Books).

(2003): "Democratic Equality Rawls's Complex Egalitarianism", en S. Freeman (ed.), The Cambridge Companion to Rawls (USA, Cambridge University Press), pp. 241-276.

DwORKIN, Ronald (1981): "What is Equality? Part 2: Equality of Resources", en Philosophy and Public Affairs, 1981b (Vol. 10, No 4), pp. 283-345.

Fatauros, Cristián (2012): "Igualdad de oportunidades y tributo sobre los talentos. Un enfoque sobre las capacidades productivas desde la óptica de la responsabilidad", en Anuario XIII del Centro de Investigaciones Jurídicas y Sociales, Facultad de Derecho y Ciencias Sociales, Universidad Nacional de Córdoba (Buenos Aires, Ed. La Ley).

HART, Herbert L. (1972): "Rawls on Liberty and its Priority", en U. Chi. L. Rev., (40), pp. 534-555.

JaCKSON, Ben (2012): "Property-Owning Democracy: A Short History", en M. O'Neill y T. Williamson, Property-Owning Democracy: Rawls and Beyond (UK, Wiley-Blackwell), pp. 33-52. 
Kymlicka, Will (2002): Contemporary Political Philosophy. An Introduction (Oxford, Oxford University Press).

MeAdE, James E. (2013): Efficiency, Equality and the Ownership of Property (UK, Routledge).

Nozıck, Robert (1990): Anarquía, Estado y utopía (México, Fondo de Cultura Económica).

O'neill, M., y Williamson, T. (2012): Property-Owning Democracy: Rawls and Beyond (UK, Wiley-Blackwell)

Pettit, Philip (1997): Republicanism: A Theory of Freedom and Government (New York, Clarendon Press).

(2008): "The Basic Liberties", En: M. Adler et al., The Legacy of H. L. A. Hart: Legal, Political, and Moral Philosophy (Oxford: Oxford University Press), pp. 201-224.

PogGe, Thomas (1989): Realizing Rawls (Ithaca, N.Y., Cornell University Press). (2007): John Rawls: His life and theory of justice (New York, Oxford University Press).

Rawls, John (1993): Political Liberalism (New York, Columbia University Press). RiвотTA, Silvina (2009): John Rawls. Sobre (des)igualdad y justicia (Madrid, Dykinson).

Saffie Gatica, Francisco (2012): "El impuesto a las herencias como una institución de justicia", en: Estudios Públicos (Vol. 126), pp. 124-161.

(2013): Taxes as Practices of Mutual Recognition: Towards a General Theory of Tax Law (Edinburgh University).

Seleme, Hugo (2013): "Equilibrio reflexivo y consenso superpuesto", en Isonomía.

Revista de Teoría y Filosofía del Derecho (Vol. 18), pp. 189-200.

Seleme, Hugo (2004): Neutralidad y justicia. En torno al liberalismo político de John Rawls (Madrid, Marcial Pons).

Vallentyne, Peter (2012): "Taxation, Redistribution and Property Rights", en: A. Marmor (Ed.), Routledge Companion to Philosophy of Law (Londres, Routledge), pp. 291-301.

VAn ParIJS, Philippe (1995): Libertad real para todos. Qué puede justificar al capitalismo (si hay algo que pueda hacerlo) (Barcelona, Paidós Ibérica).

Verbeek, Bruno (2015): "You did not Build that Road'-Reciprocity, Benefits, Opportunities and Taxing the Extremely Rich", en: Gaisbauer H., Schweiger G., Sedmak C. (Eds.), Philosophical Explorations of Justice and Taxation (Londres, Springer), pp. 67-81. 